\title{
Preferência dos cirurgiões-dentistas por atendimentos de urgência e emergência frente ao Covid-19
}

\author{
Amanda Gonçalves Franco' ${ }^{1}$ \\ Fernando Silva Miranda' \\ Aline Batista Gonçalves Franco'
}

Em 2019, no dia 31 de dezembro, a Organização Mundial da Saúde (OMS) estava alertada sobre inúmeros casos de pneumonia confirmados na província de Hubei, em Wuhan, na República Popular da China. Uma semana depois, em 7 de janeiro de 2020, as autoridades chinesas confirmaram que identificaram uma nova cepa, um novo tipo de coronavírus que ainda não havia sido identificado nos seres humanos. Esse novo vírus recebeu então o nome de SARS-CoV-2 e é considerado o causador do cenário em que vivemos, caracterizado pela OMS em 11 de março de 2020, como uma pandemia do Covid-19.

Assim como os vírus da SARS e da MERS, o novo coronavírus também é um betavírus e são capazes de causar doenças respiratórias graves, porém, esse é capaz de se disseminar de forma muito mais rápida do que os anteriores.

O grande desafio da nossa atualidade é vencer esse cenário instável e temeroso que o Covid-19 trouxe, para isso torna-se necessário tomar as devidas precauções.

Os cirurgiões-dentistas se encontram entre os profissionais que apresentam os mais altos riscos de serem contaminados pelo Covid-19. Isso se dá visto que as principais vias de transmissão e disseminação incluem a transmissão direta do vírus através de tosse, do espirro e perdigotos, além da transmissão por contato com os olhos e com as mucosas oral e nasal. Tendo em vista que as atividades odontológicas implicam em um contato direto próximo e em alguns casos, por tempo demorado, o Conselho Federal de Odontologia (CFO), exigiu, por meio do ofício $n^{\circ} 477 / 2020$, a suspensão das atividades odontológicas no país que não sejam casos de Urgência e Emergência para a contenção da pandemia.

Visando minimizar a propagação do novo coronavírus, a Associação de Medicina Intensiva Brasileira (AMIB), com o apoio do Conselho Federal de Odontologia (CFO), criou o Comitê de Odontologia de Enfrentamento à Covid-19. A parceria divulgou orientações que orientam o atendimento odontológico de cirurgiões-dentistas nos consultórios e dos agentes públicos que atuam em ambiente hospitalar, caso o atendimento seja realmente necessário.

Nesses atendimentos, devem ser realizadas todas as etapas que promovem o cuidado com a saúde do profissional e dos pacientes. Dentre elas temos primeiramente a pré-triagem, que se refere a perguntas feitas pelo próprio profissional ou secretária ao paciente por telefone para que ele esteja ciente se o paciente presenta sintomas gripais ou teve contato próximo a alguma pessoa que apresentava; o dentista defina se o tratamento a ser feito é de urgência ou emergência odontológica. Após a pré-triagem, durante a consulta, devem ser tomadas medidas de biossegurança como a higiene frequente das mãos com álcool a 70\% por no mínimo 20 segundos;

\footnotetext{
${ }^{1}$ Universidade de Itaúna. Itaúna, MG. Brasil. Correspondência para AG Franco. E-MAIL: amandagfranco38@gmail.com
} 
a utilização dos Equipamentos de Proteção Individuais (máscara, óculos de proteção, protetor facial ou viseira gorro, luvas e avental impermeável) e o descarte dos mesmos após cada paciente; a segurança durante mesmos após cada paciente; a segurança durante o
manuseio dos perfuro-cortantes; a esterilização dos manuseio dos perfuro-cortantes; a esterilização dos
instrumentos e dispositivos e, por fim, a limpeza e a instrumentos e dispositivos e, por fim, a limpeza e desinfecção das superfícies antes de cada procedimento.

Também, com o intuito de facilitar o entendimento a Secretaria de Saúde definiu os conceitos de urgências e emerrências odontológicas. Essa medida visa ressaltar que essas duas são as situações en evem realizar seus atendimentos.

As emergências odontológicas foram definidas como as situações consideradas prioridades e que, além disso, potencializam o risco de morte ao paciente. Já as urgências odontológicas, seriam então os casos que determinam prioridade para o atendimento, porém não potencializam o risco de morte ao paciente.

Com o intuito de representar os atendimentos considerados preferenciais e não preferenciais, O CFO criou um manual de maneira a organizar esses dados.

Os procedimentos de emergência, devem ser mantidos durante todo o período da a pandemia e, por serem potencialmente fatais, requerem um tratamento imediato. Esses procedimentos são:

- Os sangramentos que não conseguem ser controlados.

- As celulites e as infecções bacterianas difusas, que apresentam um aumento de volume (edema) e localizações intra ou extra-orais e um risco de comprometer as vias aéreas dos pacientes.

- Os traumatismos que envolvem os ossos da face, que também acabam por comprometer as vias aéreas dos pacientes.

Os procedimentos de urgência no tratamento odontológico, que também requerem prioridade no atendimento são:

- As dores de dente agudas, decorrente de inflamações da polpa, ou seja, as pulpites e as pericoronarites.

- As dores relacionadas aos processos infecciosos que envolvem os terceiros molares retidos.

- As dores agudas com origem na articulação temporomandibular, como por exemplo nos casos de capsulites e sinovites.

- As alveolites pós-operatórias, que requerem um controle ou uma aplicação medicamentosa local.
- As remoções de suturas dos procedimentos odontológicos.

- Os abscessos dentários e os abcessos periodontais e as infecções bacterianas, que acabam por resultar em dores localizadas e edemas.

- As fraturas de dente, que também acabam por causar dor ou, além disso, um trauma no tecido mole bucal.

Os tratamentos odontológicos necessários prévios aos procedimentos médicos mais críticos.

- As cimentações ou fixações de coroas e de próteses fixas nos casos em que a restauração provisória ou definitiva se encontra má adaptada, perdida, quebrada ou até mesmo, estiver causando dor e/ou inflamação no tecido mole da gengiva.

As biópsias que apresentam alterações anormais dos tecidos bucais.

- Os ajustes ou os reparos de próteses removíveis que acabam por gerar dor local ou o comprometimento da função mastigatória.

- As finalizações ou as trocas de medicações intracanais. Essas mesmas realizadas com hidróxido de cálcio, além dos selamentos com materiais mais resistentes à mastigação para tratamentos endodônticos já iniciados, de forma a evitar um prognóstico ruim

- As cáries extensas ou as restaurações que apresentam problemas que geram dor, como por As cailes extensas ou as restauracoes que exar a a chamas de contato prematuro.

gerar o que chamamos de contato prematuro.

- As necroses orais com presença de dor e secreção purulenta.

- Os ajustes, trocas, as remoções dos arcos ou dispositivos ortodônticos que geraram ulcerações na mucosa oral.

- As mucosites orais que apresentam indicações de tratamento com a laserterapia.

- Os traumas dentários com avulsão ou luxação.

Por último, os Procedimentos Odontológicos não classificados como Urgência odontológica, ou seja, os procedimentos não preferenciais, devem ser remarcados ou suspensos a fim de conter a pandemia do coronavírus (COVID-19). Esses procedimentos são:

As consultas de rotina e de manutenção, como as limpezas, as profilaxias e radiografias de rotina.

- Os procedimentos ortodônticos que não envolvem a presença da dor, de infecção ou de um trauma.
- As restaurações de dentes que apresentam lesões cariosas assintomáticas.

- Os procedimentos odontológicos que visam a estética apenas.

- As cirurgias eletivas, como as extrações dentárias e as cirurgias periodontais sem sintomas, como as colocações de implantes, as cirurgias ortognáticas e as demais cirurgias que não se encontram relacionadas às urgências e emergências.

Frente ao grande risco de contágio e visto que a transmissão do Covid-19 pode se dar de muitas formas, entendese assim a necessidade de reduzir os atendimentos odontógicos apenas para os realmente atendimentos odontologicos apenas para os realmente necessários, ou seja, Esses procedimentos devem ser realizados respeitando todas as medidas de segurança, visto que $\mathrm{o}$ atendimento odontológico possui especificidades que representam fatores de risco de contaminação profissional e assim, de propagação da infecção para outros.

\section{REFERÊNCIAS}

Assis C. Atendimento Odontológico nas UTls. Rev Bras Odontol. 2012;69(1) [citado 202024 Mar]. Disponíve em:<http://revodonto.bvsalud.org/scielo.php?pid=S003472722012000100016\&script=sci_arttext>.

Associação de Medicina Intensiva Brasileira. Conselho Federal de Odontologia. Recomendações AMIB/CFO para atendimento odontológico COVID19: Comitê de Odontologia AMIB/CFO de enfrentamento ao COVID-19 Departamento de Odontologia AMIB - $1^{\circ}$ Atualização 25/03/2020. 2020 Conselho Federal de Odontologia (Brasil). Painel COVID-19: açōes realizadas. Brasilia, DF, c2020 [citado em 15 Abr 2020]. Disponível em: http://coronavirus.cfo.org.br/acoes.php. Conselho Federal de Odontologia (Brasil). Painel COVID-19: orientações gerais. Braślia, DF, c2020 [citado em 15 Abr 2020] Disponível em: http://coronavirus.cfo.org.br/orientacoes.php. DISTRITO FEDERAL. Linha Guia de Saúde Bucal do Distrito Federal. Disponível em: http://www.saude.df.gov.br/ wpconteudo/uploads/2018/03/Linha-Guia-de-SB-do-DFCompleto.pdf . Acesso em: 18/03/2020

Donatelli L. Coronavírus: qual o papel do cirurgiãodentista na prevenção? [Online]. 2020 [citado 2020 Mar 10]. Disponivel em: <htps:/muw cristofolicom/ biosseguranca/5-coronavirus-qual-o-papel-do-cirurgiaodentista-na-prevencao/>.

Gandra A. Coronavírus limita atendimentos de
Odontologia a urgência e emergência [online] [citado 2020 Mar 16]. Disponivel em: <https://agenciabrasil.ebc.com br/ entos-deodontologia-urgencia-e-emergencias.

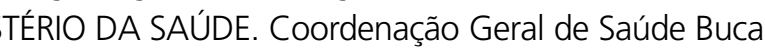
Nota Técnica no 9/2020-CGSB/DESF/SAPS/MS. Disponível em TUÑAS, Inger Teixeira de Campos; SILVA, Eduarda Teodoro da; SANTIAGO, Susana Braga Santoro; Maia, Katlin Darlen; ILVA-JÚNIOR, Geraldo Oliveira. Doença pelo Coronavírus 2019 (COVID-19): Uma abordagem preventiva para Odontologia Revista Brasileira de Odontologia. Brazilian Odournal of Dentistry. Associaça Brasilira de Odentologia Seção Rio de Janeio. Rev. Bras. Odontol. 2020:77: 1766. DOl: http://dx.doi.org/10.18363/rbo.v77.2020.e1766. 